Article

\title{
A Hybrid FCC/HZSM-5 Catalyst for the Catalytic Cracking of a VGO/Bio-Oil Blend in FCC Conditions
}

\author{
Álvaro Ibarra, Idoia Hita *, José M. Arandes (1) and Javier Bilbao (1) \\ Chemical Engineering Department, University of the Basque Country (UPV/EHU), P.O. Box 644, \\ 48080 Bilbao, Spain; aibarra.baroja@gmail.com (Á.I.); josemaria.arandes@ehu.eus (J.M.A.); \\ javier.bilbaoe@ehu.eus (J.B.) \\ * Correspondence: idoia.hita@ehu.eus
}

Received: 17 August 2020; Accepted: 17 September 2020; Published: 9 October 2020

check for updates

\begin{abstract}
The performance of a commercial FCC catalyst (designated as CY) and a physically mixed hybrid catalyst ( $80 \mathrm{wt} . \% \mathrm{CY}$ and $20 \mathrm{wt}$ \% HZSM-5-based catalyst, designated as $\mathrm{CH}$ ) have been compared in the catalytic cracking of a vacuum gasoil (VGO)/bio-oil blend (80/20 wt.\%) in a simulated riser reactor $\left(\mathrm{C} / \mathrm{O}, 6 \mathrm{~g}_{\text {cat }} \mathrm{g}_{\text {feed }}{ }^{-1} ; \mathrm{t}, 6 \mathrm{~s}\right)$. The effect of cracking temperature has been studied on product distribution (carbon products, water, and coke) and product lumps: $\mathrm{CO}+\mathrm{CO}_{2}$, dry gas, liquified petroleum gases (LPG), gasoline, light cycle oil (LCO), heavy cycle oil (HCO), and coke. Using the $\mathrm{CH}$ catalyst, the conversion of the bio-oil oxygenates is ca. $3 \mathrm{wt} . \%$ higher, while the conversion of the hydrocarbons in the mixture is lower, yielding more carbon products (83.2-84.7 wt.\% on a wet basis) and less coke (3.7-4.8 wt.\% on a wet basis) than the CY catalyst. The $\mathrm{CH}$ catalyst provides lower gasoline yields (30.7-32.0 wt. \% on a dry basis) of a less aromatic and more olefinic nature. Due to gasoline overcracking, enhanced LPG yields were also obtained. The results are explained by the high activity of the HZSM- 5 zeolite for the cracking of bio-oil oxygenates, the diffusional limitations within its pore structure of bulkier VGO compounds, and its lower activity towards hydrogen transfer reactions.
\end{abstract}

Keywords: catalytic cracking; FCC; VGO; bio-oil; gasoline; HZSM-5 zeolite

\section{Introduction}

The road to sustainability from a fossil-dependent energetic scenario to a more sustainable one brings about a number of technical, economical, and societal challenges. Among these, adapting existing refinery structures for a more versatile and efficient operation is of crucial importance. In this transition, incorporating lignocellulosic biomass in biorefinery platforms is a viable strategy for the production of "green" fuels and chemicals, while simultaneously reducing oil consumption and greenhouse gas emissions [1,2]. Bio-oil attracts great interest as a biorefinery platform because it can be upgraded to renewable or blended hydrocarbon fuels through a number of routes [3,4]. This interest is grounded in the technological development attained for bio-oil production through biomass fast pyrolysis, with simple technologies of low environmental impact [5].

The complex bio-oil composition consists of a plethora of oxygenated compounds of very different functionalities (i.e., acids, alcohols, aldehydes, esters, ketones, phenolics, guaiacols, sugars, pyrolytic lignin), together with a significant water content of 15-35 wt.\% [6,7]. Despite its low $\mathrm{N}$ and $\mathrm{S}$ content, direct application of bio-oil as a fuel is limited due to its high oxygen and water content, low calorific power, viscosity $\left(10-100 \mathrm{cP}\right.$ at $\left.40{ }^{\circ} \mathrm{C}\right)$, acidity $(\mathrm{pH} \approx 2-4)$, corrosive nature, and low chemical stability upon storage, among others $[8,9]$. For these reasons, prior to its valorization, it is also plausible to stabilize the bio-oil by removing some of the more unstable oxygenates through the addition of a solvent [10], thermal aging [11], or some catalytic treatment (i.e., esterification, 
mild hydrodeoxygenation) [12,13]. Nonetheless, these pre-treatments might be costly and can also potentially decrease the yields of interesting products in subsequent catalytic valorization stages, and hence, the interest for developing large-scale direct bio-oil conversion routes is reinforced.

Among the bio-oil upgrading routes available, its co-processing in fluid catalytic cracking (FCC) units together with conventional feedstock (vacuum gasoil, VGO) is technically feasible [14-16]. Nonetheless, significant differences are observed in the product yields depending on the production and conditioning methods for bio-oil, as well as the type of reactor, catalyst, and reaction conditions [17-24]. In any case, the economic analysis evidences the importance of using already existing refinery infrastructure for decreasing the cost of the gasoline product. This way, the price of the gasoline produced through co-feeding of bio-oil in the FCC unit is estimated to be similar to fossil-derived gasoline, while it also depends on the bio-oil characteristics and the VGO/bio-oil blend ratio [25]. Bhatt et al. [26] recently reported an analysis of the FCC unit capacity in US refineries and the effect of the co-feeding of different VGO/bio-oil ratios on the produced emissions. This study is based on the results from the Renewable Energy Laboratory (NREL) and resolves that 55 out of 95 refineries with FCC units in the US could co-process a $20 \mathrm{wt}$.\% bio-oil without requiring any major modification. Another 34 refineries can process $4-20 \mathrm{wt}$.\% bio-oil, while only the remaining six would require significant modifications in order to comply with environmental legislation. This FCC unit capacity corresponds to 573,000 barrels per day of raw bio-oil, which represent 1.92 billion gallons of gasoline equivalent per year.

The presence of oxygenates in the bio-oil/VGO blend leads to synergistic effects, which cause an increase in the dry gas yield $\left(C_{1}-C_{2}\right)$, decrease in $C_{3}-C_{4}$ hydrocarbons, and also increase the concentration of aromatics and oxygenates in the gasoline fraction. The profusion of hydride transfer reactions from hydrocarbons to oxygenates as well as the preferential adsorption of some compounds in the mixture on the acid sites of the catalyst, as well as the different diffusional restrictions when the blend is fed, can explain the main reaction synergies. In a previous work, we demonstrated the existence of a relationship between the mechanisms for the cracking of the hydrocarbons from the VGO and the oxygenates contained in raw bio-oil [21]. Through co-feeding, positive synergies are created for preventing unwanted product formation, and catalyst deactivation is also mitigated. Coke formation occurs through a dual mechanism where oxygenates and hydrocarbons act as precursors in which water also plays a relevant role attenuating their evolution towards condensed coke structures [27].

Typically, the catalyst used in the FCC process consists of a crystalline HY zeolite, embedded into a matrix containing meso- and macropores. This configuration minimizes diffusional limitations of bulky molecules towards the inner pore structure and retains the metals present in the feed [28]. In addition, the HZSM- 5 zeolite is used as catalyst additive in FCC units, which contributes to increasing the octane number of the gasoline and also helps increase the yields of olefins in the LPG fraction, to the detriment of the less profitable dry gas $[29,30]$. The shape selectivity and moderate acidity of the HZSM- 5 zeolite are suitable for minimizing secondary bimolecular and hydrogen transfer reactions, hence favoring the selectivity towards olefins and minimizing the yields of coke and undesired overcracking products (i.e., $\mathrm{CH}_{4}, \mathrm{CO}$ and $\mathrm{CO}_{2}$ ). The activity and stability of the HZSM-5 zeolite have been already reported for the production of bio-oil through catalytic biomass pyrolysis [31] as well as for the selective production of light olefins from raw bio-oil [32].

This manuscript compares the performance at different temperatures $\left(500-530-560{ }^{\circ} \mathrm{C}\right)$ of a commercial FCC catalyst (containing HY zeolite, designated as CY) and a physically mixed hybrid catalyst (designated as $\mathrm{CH}$ ) consisting of $80 \mathrm{wt} . \%$ commercial FCC (CY) and $20 \mathrm{wt} . \%$ of a HZSM-5-based catalyst (designated as CZ), on the fluid catalytic cracking of a VGO/bio-oil blend (80/20 wt.\%) and resembling industrial conditions $\left(\mathrm{C} / \mathrm{O}, 6 \mathrm{~g}_{\text {cat }} \mathrm{g}_{\text {feed }}{ }^{-1}\right.$; contact time, $\left.6 \mathrm{~s}\right)$. By adding the HZSM- 5 additive to the commercial FCC catalyst, the goal of this study is to determine its effect on the main product distribution as well as individual product lumps, and on the quality of the produced gasoline. The obtained results evidence the potential of the HZSM- 5 zeolite as a catalyst additive not only for the habitual VGO cracking, but also for the co-cracking of a VGO/bio-oil blend. Furthermore, co-feeding 
raw bio-oil together with VGO provides new knowledge with respect to studies on the conversion of model compounds of bio-oil. The utilization of equilibrated catalysts and also a laboratory reaction setup, which resembles industrial operation, allows for obtaining realistic and industrially meaningful results in order to progress towards a great-scale bio-oil valorization.

\section{Results and Discussion}

\subsection{Effect of Reaction Temperature on Conversion and Main Cracking Product Yields on a Wet Basis}

The evolution with temperature of the conversion as well as the carbon products, water, and coke yields (the values correspond to product distribution, calculated in a wet basis, see Equation (1)) are displayed in Figure 1. In terms of conversion (Figure 1a), it increases with temperature and results ca. $3 \mathrm{wt} . \%$ lower using the hybrid $\mathrm{CH}$ catalyst in contrast to the $\mathrm{CY}$ catalyst (56.2 and $58.9 \mathrm{wt} . \%$ at $500{ }^{\circ} \mathrm{C} ; 68.6$ and $71.8 \mathrm{wt} . \%$ at $560^{\circ} \mathrm{C}$, respectively). This lower conversion of the $\mathrm{CH}$ catalyst can be attributed to the diffusional limitations that the HZSM- 5 zeolite presents for bulkier feed molecules, mostly contained in VGO. This more severe shape selectivity (with narrower pores) eventually leads to a lesser conversion of this heavier VGO fraction. In addition, cracking reactions require strongly acidic Brönsted sites, which are more abundant in the CY catalyst (see Section 3.1). On the other hand, the yields of the main cracking products on a wet basis in Figure $1 \mathrm{~b}$ show that the yields of carbon products, which are the dominant reaction products, are slightly higher for the $\mathrm{CH}$ catalyst (83.2-84.7 wt.\%), with a lower coke formation (3.7-4.8 wt.\%), while water yield (11.5-12.0 wt.\%) is very similar for both catalysts. These results indicate that the formation of carbon products in the volatiles is hindered by higher cracking temperatures, which simultaneously favor the formation of coke deposits on the catalyst. It should be mentioned that despite the issues that arise in bio-oil valorization processes from the rapid repolymerization of phenolics and the formation of the so-called thermal lignin [13], no operational issues derived from coke formation were observed in this study. This can be explained by the elevated cracking temperatures of this study and the fast kinetics of the reactions taking place. Furthermore, the fluidization of the catalyst particles and the significant water content in the reaction media also aid to hinder the aforementioned repolymerization reactions.

On the other hand, the almost constant water yields suggest that deoxygenation reactions (which generally form water as an end product) are not significantly affected by temperature variations, which tend to affect cracking and (de)hydrogenation reactions in a greater extent. Even though a higher acidity of the catalyst is known to have a great impact on promoting deoxygenation reactions [12,24], in this case, the inclusion of the HZSM-5 zeolite in the catalyst bed did not reflect such big effect on water formation (Figure 1b), likely due to its dilution in the $\mathrm{CH}$ catalyst, and also its low proportion (20 wt.\%) in the physical catalyst mixture.
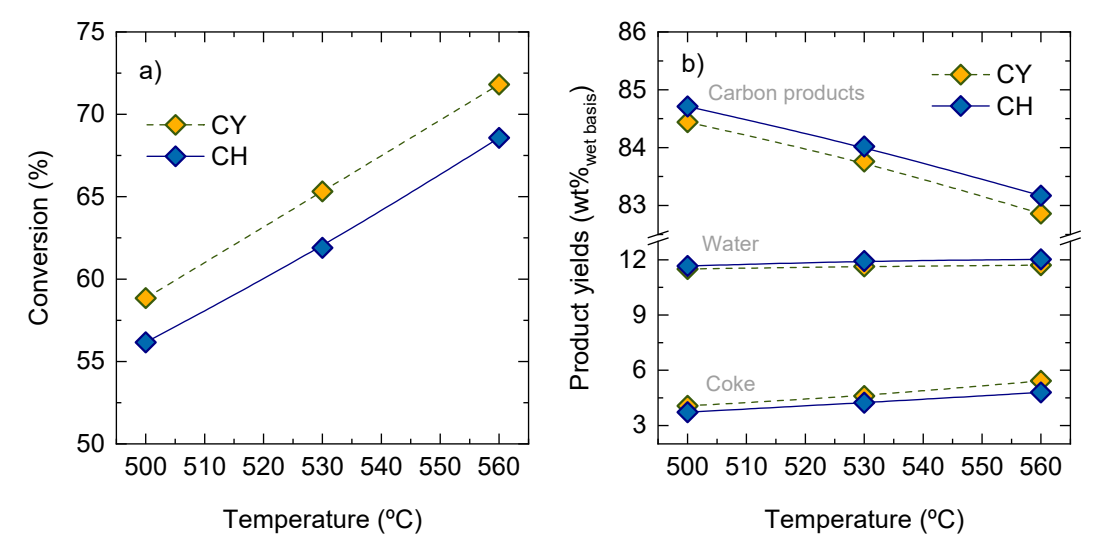

Figure 1. Effect of the reaction temperature on (a) the conversion of the vacuum gasoil (VGO)/bio-oil blend (80/20 wt.\%) and (b) the main cracking product yields (on a wet basis) using the $\mathrm{CY}$ and $\mathrm{CH}$ catalysts $\left(\mathrm{C} / \mathrm{O}, 6 \mathrm{~g}_{\text {cat }} \mathrm{g}_{\text {feed }}{ }^{-1}\right.$; contact time, $\left.6 \mathrm{~s}\right)$. 
Table 1 correlates the coke content deposited on the $\mathrm{CY}$ and $\mathrm{CH}$ catalysts in the experiments reported in Figure 1. Coke content increases upon increasing the reaction temperature, as a consequence of an enhancement of the formation of polyaromatic compounds through condensation of reaction intermediates. In this mechanism, aromatics play a key role. It should also be mentioned that the coke contents are slightly below those reported for the catalytic cracking of VGO alone. Ibarra et al. [33] have explained the synergies in the coke formation mechanism in the co-cracking of a VGO/bio-oil blend, observing that co-feeding bio-oil plays a favorable role due to the presence of water in the reaction media as well as the occurrence of hydrogen transfer reactions from the hydrocarbons in VGO towards coke precursors. The higher coke deposition in the CY catalyst can also be associated to the presence of stronger acidic sites (mainly Brönsted, see Section 3.1), which are particularly active in coke formation reactions.

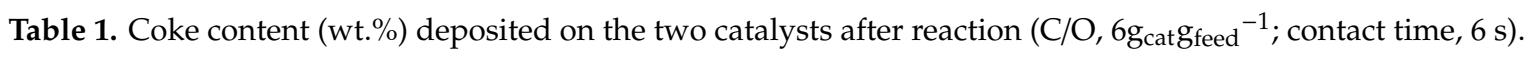

\begin{tabular}{lccc}
\hline & $\mathbf{5 0 0}{ }^{\circ} \mathbf{C}$ & $\mathbf{5 3 0}^{\circ} \mathbf{C}$ & $\mathbf{5 6 0}^{\circ} \mathbf{C}$ \\
\hline $\mathrm{CY}$ & 0.675 & 0.765 & 0.897 \\
$\mathrm{CH}$ & 0.628 & 0.707 & 0.795 \\
\hline
\end{tabular}

The deterioration of the catalyst properties as a consequence of coke deposition can be evaluated by comparing the properties of both spent catalysts at $500{ }^{\circ} \mathrm{C}$ (Table 2) with their properties in fresh catalyst conditions (see Section 3.1). To facilitate this comparison, Table 2 also includes the relative change (in \%) of each parameter. It must be highlighted that the properties of the fresh $\mathrm{CH}$ catalyst have been calculated as a weighted average of the catalysts, which form the $\mathrm{CH}$ mixture $(80 \mathrm{wt} . \%$ $\mathrm{CY}$ and $20 \mathrm{wt}$.\% of $\mathrm{CZ}$ catalyst). However, the properties of the spent $\mathrm{CH}$ catalyst correspond to the mixture, due to the difficulty for separating the two mixed catalysts after reaction. We observed that, after reaction, the physical (BET surface area, pore, and micropore volume) and acidic properties (total acidity, average acidic strength) of the CY catalyst decrease in a greater extent than those of the $\mathrm{CH}$ catalyst. This is in agreement with the well-established stability of the HZSM- 5 zeolite in coke deposition conditions [34-36]. It was also observed that coke preferentially blocks the micropore structure in both catalysts, hence increasing the average pore diameter in the used catalysts. In addition, we also observed a selective deactivation of the Brönsted acidic sites, which are stronger and more active in aromatic condensation reactions towards coke formation.

Table 2. Physico-chemical properties of the spent catalysts and their relative variation with respect to fresh catalyst conditions.

\begin{tabular}{ccccc}
\hline- & CY Used & $\boldsymbol{\Delta}(\mathbf{\%})$ & CH Used & $\boldsymbol{\Delta}(\mathbf{\%})$ \\
\hline $\mathrm{S}_{\mathrm{BET}}\left(\mathrm{m}^{2} \mathrm{~g}^{-1}\right)$ & 85 & -31 & 92 & -27 \\
$\mathrm{~V}_{\text {pore }}\left(\mathrm{cm}^{3} \mathrm{~g}^{-1}\right)$ & 0.18 & -50 & 0.2 & -40 \\
$\mathrm{~V}_{\text {micropore }}\left(\mathrm{cm}^{3} \mathrm{~g}^{-1}\right)$ & 0.02 & -50 & 0.03 & -30 \\
$\mathrm{~d}_{\mathrm{p}}(\AA)$ & 208 & 80 & 170 & 60 \\
Total acidity $\left(\mu \mathrm{mol}_{\mathrm{NH} 3} \mathrm{~g}^{-1}\right)$ & 24 & -20 & 26 & -24 \\
Average acid strength $\left(\mathrm{kJ} \mathrm{mol}^{-1}\right)$ & 71 & -29 & 65 & -32 \\
Brönsted/Lewis $(\mathrm{B} / \mathrm{L})$ ratio $\left(\mathrm{mol} \mathrm{mol}^{-1}\right)$ & 0.33 & -50 & 0.28 & -59 \\
\hline
\end{tabular}

\subsection{Effect of Reaction Temperature on Conversion and Product Lump Distribution on a Dry Basis}

The yields of the different product lumps on a dry bio-oil basis for the two catalysts present clear differences, as depicted in Figure 2. The lower yield of the gasoline fraction (Figure 2d) through the whole temperature range when using the $\mathrm{CH}$ catalyst (30.7-32.0 wt.\%) should be noted, as a consequence not only of its overcracking towards LPG (Figure 2c, with yields of 16.6-21.6 wt.\%), but also of a lower conversion of the heaviest fraction of VGO, as previously discussed from Figure 1 a. These heavy components will find limitations on their diffusion within the micropores of the HZSM- 5 
zeolite and even in the matrix of this catalyst, which lacks macropores. As a consequence, the yields of the heavier LCO and HCO lumps (Figure 2e,f) are higher when using the $\mathrm{CH}$ catalyst (20.4-22.3 wt.\% and 9.6-18.4 wt.\%, respectively). The coke yield (Figure $2 \mathrm{~g}$ ) was slightly lower with the $\mathrm{CH}$ catalyst (4.3-5.7 wt.\%). Furthermore, despite the higher gasoline overcracking that occurs with the $\mathrm{CH}$ catalyst, the $\mathrm{CO}+\mathrm{CO}_{2}$ yield (Figure 2a) was analogue for both catalysts (1.4-2.1 wt.\%), while the dry gas yield (Figure $2 b$ ) was slightly lower for the $\mathrm{CH}$ catalyst (6.2-10.0 wt.\%).

The capacity of HZSM-5 zeolites for boosting the formation of LPGs in the cracking of raw bio-oil has previously been reported [24], as well as its higher selectivity for the formation of light olefins, to the detriment of decarbonylation, decarboxylation, and decomposition reactions, towards $\mathrm{CO}, \mathrm{CO}_{2}$, and methane, respectively [34]. Furthermore, the tridimensional pore structure of the HZSM-5 zeolite also likely plays an important role for facilitating the diffusion of coke precursors towards the exterior of the catalyst particle [35,36]. In this study, the sweeping of coke precursors is also boosted by the presence of water in the reaction medium, which originates from both the bio-oil feed (see Table S1) and deoxygenation reactions of bio-oil oxygenates.
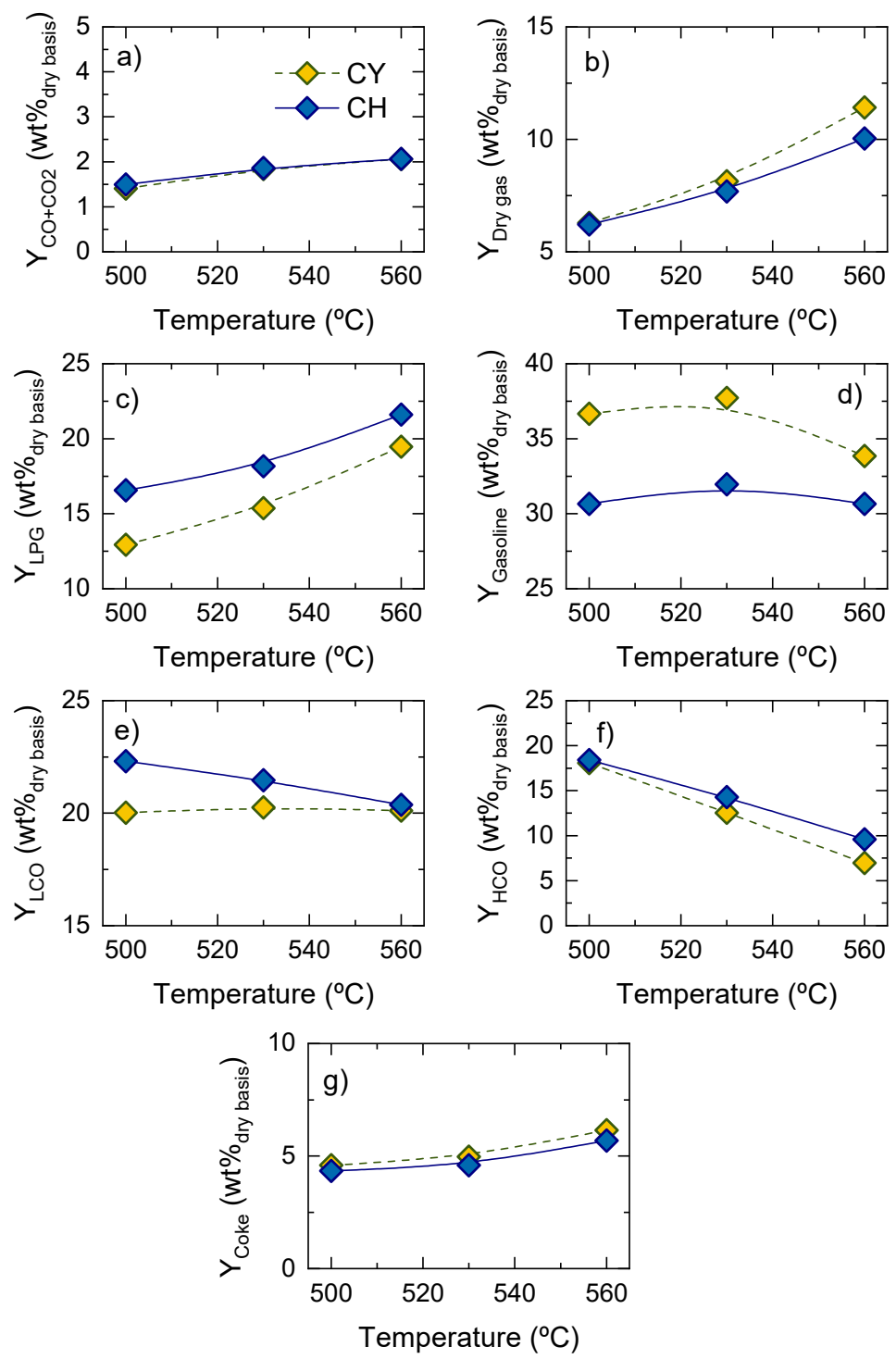

Figure 2. Effect of temperature over the yields of (a) $\mathrm{CO}+\mathrm{CO}_{2}$, (b) dry gas, (c) LPG, (d) gasoline, (e) LCO, (f) HCO and (g) coke on the catalytic cracking of a VGO/bio-oil blend using the $\mathrm{CY}$ and $\mathrm{CH}$ catalysts $\left(\mathrm{C} / \mathrm{O}, 6 \mathrm{~g}_{\text {cat }} \mathrm{g}_{\text {feed }}{ }^{-1}\right.$; contact time, $\left.6 \mathrm{~s}\right)$. 
Figure S1 displays the comparison of the evolution with conversion of the dry gas, LPG, and gasoline yields for both catalysts. The higher gasoline overcracking capacity of the hybrid $\mathrm{CH}$ catalyst is manifested not only because of the lower gasoline yields (Figure S1c), but also because the maximum gasoline yield corresponds to a lesser advance of the reaction. As a consequence of overcracking being favored, the yield of LPGs is higher using the $\mathrm{CH}$ catalyst (Figure S1b) and the difference between the two catalysts is maintained upon increasing the conversion, with no significant increase in the yield of dry gas (Figure S1a).

In addition to the notable effect that temperature has on the product yields, this variable also has a significant influence in the composition of the different product fractions. Specifically, for gas products, the use of the $\mathrm{CH}$ catalyst leads to an overall increase in the yields of light olefins, as shown in Figure S2. Within the whole studied temperature range, the $\mathrm{CH}$ catalyst provides higher yields of ethylene and lower yields of ethane and methane (Figure S2a). In the $\mathrm{C}_{3}$ fraction (Figure S2b), also a higher yield of propylene and propane was observed for the $\mathrm{CH}$ catalyst, while in the $\mathrm{C}_{4}$ fraction, an increase in all gas species was detected (Figure S2c,d). The olefinity ratios summarized in Table 3 indicate that, using the $\mathrm{CH}$ catalyst, higher gas yields (see Figure 2) also imply a selective increase in olefins, which is explained by the limited activity of the HZSM-5 zeolite in hydrogen transfer reactions in FCC reaction conditions [37]. It was observed that the production of specifically ethylene and butene (with respect to ethane and butane) is boosted by using the hybrid catalyst, as the HZSM-5 intervenes in the oligomerization-cracking mechanism of interconversion of light olefins [38].

Table 3. Comparison of the effect of temperature on the olefinity of the $C_{2}-C_{4}$ families in the gas products during the cracking of the $\mathrm{VGO} /$ bio-oil blend using the $\mathrm{CY}$ and $\mathrm{CH}$ catalysts $\left(\mathrm{C} / \mathrm{O}, 6 \mathrm{~g}_{\text {cat }} \mathrm{g}_{\text {feed }}{ }^{-1}\right.$; contact time, $6 \mathrm{~s})$.

\begin{tabular}{ccccc}
\hline- & Catalyst & $\mathbf{5 0 0}{ }^{\circ} \mathbf{C}$ & $\mathbf{5 3 0}{ }^{\circ} \mathbf{C}$ & $\mathbf{5 6 0}{ }^{\circ} \mathbf{C}$ \\
\hline $\mathrm{C}_{2}=/ \mathrm{C}_{2}$ Total. & $\mathrm{CY}$ & 0.63 & 0.66 & 0.65 \\
$\mathrm{C}_{3}=/ \mathrm{C}_{3}$ Total & $\mathrm{CH}$ & 0.78 & 0.80 & 0.75 \\
$\mathrm{C}_{4}=/ \mathrm{C}_{4}$ Total & $\mathrm{CY}$ & 0.75 & 0.73 & 0.72 \\
& $\mathrm{CH}$ & 0.75 & 0.74 & 0.73 \\
& $\mathrm{CY}$ & 0.48 & 0.49 & 0.51 \\
\hline
\end{tabular}

\subsection{Composition of the Gasoline Fraction}

In Table 4, the conversion of the oxygenates in bio-oil, deoxygenation degree, liquid fuel and oxygen-to-carbon ratio of the liquid fuel are compared for the three studied temperatures using the $\mathrm{CY}$ and $\mathrm{CH}$ catalysts. It was observed that the conversion of bio-oil oxygenates is favored by the presence of the HZSM- 5 catalyst, being higher using the $\mathrm{CH}$ catalyst. This way, the conversion with this catalyst is of $86.0 \mathrm{wt} . \%$ and of $82.6 \mathrm{wt} . \%$ using the $\mathrm{CY}$ catalyst at $500{ }^{\circ} \mathrm{C}$, and the difference decreases upon increasing temperature (93.4 and $91.2 \mathrm{wt} . \%$ at $560^{\circ} \mathrm{C}$ for the $\mathrm{CH}$ and $\mathrm{CY}$ catalysts, respectively).

In the catalytic cracking of VGO/bio-oil mixtures, a variety of different types of compounds are formed through a series of deoxygenation, cracking, dehydration, decarboxylation, decarbonylation, and alkylation reactions, among the most important ones. Specifically, when co-processing two feeds of such distinct nature as VGO and bio-oil, an insightful assessment of the gasoline quality requires evaluating the composition of the oxygenates and hydrocarbons separately.

As observed in the results discussed in Figure 2, gasoline is the main product fraction of the catalytic cracking of the VGO/bio-oil blend, using either the commercial CY catalyst (33.9-37.7 wt.\%) or the hybrid $\mathrm{CH}$ one (30.7-32.0 wt.\%). The results in Table 4 and Figure 2 indicate that the conversion of the oxygenates in the bio-oil feedstock, as well as deoxygenation degree (DOD) is favored upon increasing cracking temperature, and particularly using the $\mathrm{CH}$ catalyst. On the other hand, the yields towards liquid fuels decrease upon increasing cracking temperature, as a consequence of promoted gasoline overcracking. It was also observed that gasoline produced at higher temperatures is slightly more 
deoxygenated. The diffusional limitations that the HZSM- 5 zeolite offers for the bigger hydrocarbons contained in the LCO and HCO fractions of VGO, and the simultaneous promotion of selective deoxygenation and cracking reactions of bio-oil oxygenates, are the explanation for these results. In addition, the overcracking of the gasoline components originating from VGO is also boosted in a lesser extent. Due to this high deoxygenation, the liquid fuel obtained with the $\mathrm{CH}$ catalyst offers better perspectives for its use.

Table 4. Comparison of the effect of temperature over the bio-oil conversion $\left(\mathrm{X}_{\text {oxygenates }}\right)$, deoxygenation degree (DOD), yields of liquid fuel $\left(\mathrm{Y}_{\text {fuel }}\right)$, and oxygen-to-carbon ratio $\left(\mathrm{O}_{\mathrm{x}} / \mathrm{C}\right)$ of the liquid fuel obtained in the catalytic cracking of the VGO/bio-oil blend using the $\mathrm{CY}$ and $\mathrm{CH}$ catalysts $\left(\mathrm{C} / \mathrm{O}, 6 \mathrm{~g}_{\text {cat }} \mathrm{g}_{\text {feed }}{ }^{-1} ; \mathrm{t}, 6 \mathrm{~s}\right)$.

\begin{tabular}{ccccc}
\hline- & Catalyst & $\mathbf{5 0 0}^{\circ} \mathbf{C}$ & $\mathbf{5 3 0}{ }^{\circ} \mathbf{C}$ & $\mathbf{5 6 0}{ }^{\circ} \mathbf{C}$ \\
\hline \multirow{2}{*}{$\mathrm{X}_{\text {oxygenates }}$} & $\mathrm{CY}$ & 82.6 & 87.1 & 91.2 \\
& $\mathrm{CH}$ & 86.0 & 89.5 & 93.4 \\
\hline \multirow{2}{*}{$\mathrm{DOD}$} & $\mathrm{CY}$ & 91.0 & 93.0 & 95.0 \\
& $\mathrm{CH}$ & 92.5 & 95.1 & 96.7 \\
\hline \multirow{2}{*}{$\mathrm{Y}_{\text {fuel }}$} & $\mathrm{CY}$ & 62.2 & 59.3 & 51.9 \\
& $\mathrm{CH}$ & 60.3 & 56.9 & 50.3 \\
\hline \multirow{2}{*}{$\mathrm{O}_{\mathbf{x}} / \mathrm{C}$} & $\mathrm{CY}$ & 0.10 & 0.09 & 0.08 \\
& $\mathrm{CH}$ & 0.09 & 0.08 & 0.08 \\
\hline
\end{tabular}

As previously discussed, due to the more severe shape selectivity of the HZSM-5 zeolite as well as its gasoline overcracking capacity, the hybrid $\mathrm{CH}$ catalyst provides lower gasoline yields. Furthermore, the gasoline produced with the two different catalysts differs notably in composition, as shown in Figure 3. Using the $\mathrm{CH}$ catalyst, a lower yield of aromatics was observed $(9.1 \mathrm{wt} . \%)$. This higher yield of aromatics (11.6 wt.\%) using the CY catalyst can be justified by (i) the breakage of bonds in the aromatic compounds in the LCO fraction (which does not easily access the HZSM- 5 pore structure) and (ii) the low activity of the HZSM-5 zeolite in bimolecular hydrogen transfer reactions, olefin oligomerization and Diels-Alder condensation in FCC reactor unit conditions [37]. The higher proportion of strongly acidic Brönsted sites (active for these reactions) in the CY catalyst (Table 5) is in agreement with its higher activity for the formation of aromatics. On the other hand, the yields of naphthenics, olefins, and i-paraffins are slightly lower for the $\mathrm{CH}$ catalyst (2.3 wt.\%, $9.3 \mathrm{wt} . \%$, and $3.8 \mathrm{wt} . \%$, respectively), due to the enhancement of the monomolecular cracking of all these fractions towards LPGs promoted by the HZSM-5 zeolite.

For a more detailed evaluation of the hydrocarbon composition in gasoline, Figure 4 compares the distribution of each of the gasoline hydrocarbon compound families on a carbon number basis for both catalysts. Among aromatics (Figure 4a), all compound yields were lower using the $\mathrm{CH}$ catalyst, specifically those in the $\mathrm{C}_{8}-\mathrm{C}_{10}$ range, which are the most abundant and originate from the dealkylation and bond breakage of heavy aromatics in the LCO and HCO fractions. This decrease in aromatics in gasoline using the hybrid $\mathrm{CH}$ catalyst presents a clear commercial interest, aiming for the incorporation of this gasoline into the refinery pool. On the other hand, the concentrations of n-paraffins (Figure 4b), olefins (Figure 4c), and i-paraffins (Figure 4d) are overall lower than those of aromatics. It was observed that $\mathrm{CH}$ catalyst slightly favors the cracking of these species, with the exception of the $\mathrm{C}_{11}-\mathrm{C}_{12}$ paraffins, whose diffusion is likely limited within the HZSM-5 pore structure. 


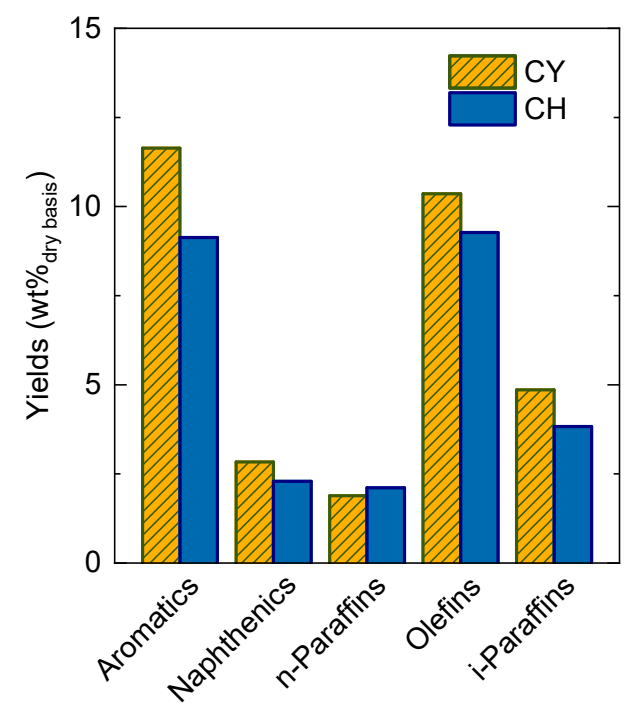

Figure 3. Comparison of the yields of the hydrocarbon families of the gasoline fraction produced from the catalytic cracking of a VGO/bio-oil blend using the $\mathrm{CY}$ and $\mathrm{CH}$ catalysts $\left(\mathrm{C} / \mathrm{O}, 6 \mathrm{~g}_{\text {cat }} \mathrm{g}_{\text {feed }}{ }^{-1}\right.$; contact time, $6 \mathrm{~s})$.
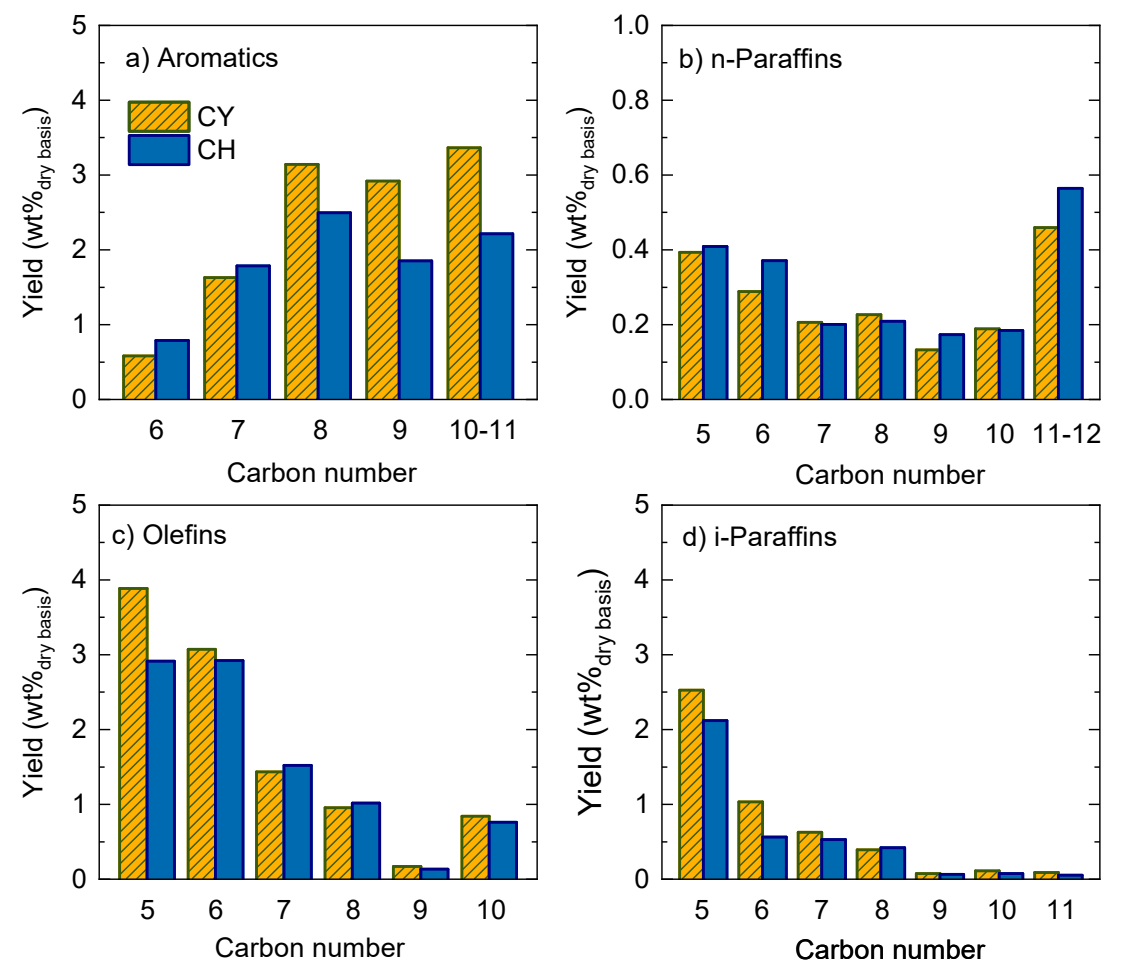

Figure 4. Comparison of the yields of (a) aromatics, (b) n-paraffins, (c) olefins and (d) i-paraffins of the gasoline hydrocarbon fraction (on the basis of their carbon number) produced from the catalytic cracking of a VGO/bio-oil blend using the $\mathrm{CY}$ and $\mathrm{CH}$ catalysts $\left(\mathrm{C} / \mathrm{O}, 6 \mathrm{~g}_{\text {cat }} \mathrm{g}_{\text {feed }}{ }^{-1}\right.$; contact time, $\left.6 \mathrm{~s}\right)$.

Another important aspect is the decrease in the isomerization activity of the catalyst after incorporating the HZSM-5 zeolite. As a consequence, as listed in Table S2, the $\mathrm{C}_{5}$ and $\mathrm{C}_{6}$ iso-olefin fractions decrease, as well as the $C_{5}$ and $C_{5}$ iso-paraffin fractions (summarized in Table S3). The effect over the olefinity of the gasoline fraction (Table S2) is dependent on temperature. At $500{ }^{\circ} \mathrm{C}$ gasoline has a less olefinic nature, while, at higher temperatures of $560^{\circ} \mathrm{C}$, when hydrogen transfer reactions are attenuated, a more olefinic gasoline is produced. Within the whole studied temperature range, 
this olefinity index was higher when using the commercial $C Y$ catalyst, which indicates that the attenuation of hydrogen transfer reactions is higher for the HZSM-5 zeolite in the $\mathrm{CH}$ catalyst.

\section{Materials and Methods}

\subsection{Catalyst Synthesis and Characterization}

Two zeolite-based catalysts were used in this study: (i) an equilibrated industrial FCC catalyst, directly sampled from the outlet stream of a FCC unit from Petronor S.A. (Somorrostro, Spain), containing $15 \mathrm{wt} . \% \mathrm{HY}$ zeolite and that has been equilibrated in subsequent reaction-regeneration cycles in the industrial unit and (ii) a catalyst based on HZSM- 5 zeolite (supplied by Zeolyst International, $\mathrm{SiO}_{2} / \mathrm{Al}_{2} \mathrm{O}_{3}=80$ ), which has been calcined at $550{ }^{\circ} \mathrm{C}$ under a $\mathrm{N}_{2}$ stream for $4 \mathrm{~h}$, and subsequently agglomerated in a matrix by wet extrusion of the active phase (zeolite, $20 \mathrm{wt} . \%$ ), binder (bentonite, $2 \mathrm{wt} . \%)$, and inert filler $\left(\alpha-\mathrm{Al}_{2} \mathrm{O}_{3}, 78 \mathrm{wt} . \%\right)$. This agglomeration in a meso- and macroporous matrix leads to the formation of a hierarchical porous structure in the catalyst particle within which sequential reactant diffusion takes place and partial cracking of bulkier feedstock molecules occurs, followed by a subsequent cracking of the resulting chains within the micropore structure of the catalyst [24]. After agglomeration, the catalysts were dried, calcined at $550{ }^{\circ} \mathrm{C}$, milled, and sieved to the desired particle size $(60-120 \mu \mathrm{m})$. Finally, the HZSM-5-based catalyst was equilibrated through a steaming treatment, for $5 \mathrm{~h}$ at $760{ }^{\circ} \mathrm{C}$ and atmospheric pressure. This treatment causes partial dealumination of the zeolites, removing strongly acidic centers from the catalytic surface, which are highly unstable and not capable of fully recovering their activity in successive reaction-regeneration stages [38]. Steaming treatments will also enhance the mesoporous structure of the catalysts, thus increasing the average pore diameter and enabling the accessibility of heavy feed components into the zeolite pores. This catalyst equilibration is necessary in order to attain results that are representative of an industrial FCC unit. The effectivity of the steaming treatment was corroborated in a pre-experimental phase through experiments with intermediate regeneration (complete coke combustion in air at $550{ }^{\circ} \mathrm{C}$ ) after which the catalysts totally recovered their activity. The catalysts have been designated as (i) CY (equilibrated FCC) and (ii) CZ (HZSM-5-based), respectively. The hybrid catalyst consists of the physical mixture of both catalysts in a CY/CZ mass ratio of $80 / 20 \mathrm{wt} . \%$ and was designated as $\mathrm{CH}$.

The physical properties, BET surface area, and pore structure of the fresh catalysts were determined by $\mathrm{N}_{2}$ adsorption-desorption at $-196{ }^{\circ} \mathrm{C}$ in an ASAP 2010 unit by Micromeritics (Norcross, GA, USA), after previously degassing the sample at $150{ }^{\circ} \mathrm{C}$ for $8 \mathrm{~h}$ under vacuum conditions (see isotherms in Figure S3). The specific surface are $\left(\mathrm{S}_{\mathrm{BET}}\right)$ was computed using the Brunauer-Emmett-Teller (BET) equation, while the micropore volume $\left(\mathrm{V}_{\text {micropore }}\right)$ was calculated using the $t$-method, based on the Harkins-Jura equation. The BJH method was applied for estimating the average pore size $\left(\mathrm{d}_{\mathrm{p}}\right)$. Mesopore volume $\left(\mathrm{V}_{\text {mesopore }}\right)$ was calculated from the difference between total pore volume $\left(\mathrm{V}_{0.995}\right)$ and micropore volume. The crystalline structure was studied through X-ray diffraction in a PW 1710 apparatus by Philips (Amsterdam, The Netherlands) (see XRD patterns in Figure S4). The total acidity and strength of acidic sites were determined by isothermal adsorption of $\mathrm{NH}_{3}$ at $150{ }^{\circ} \mathrm{C}$ followed by a temperature programmed desorption (TPD) up to $550{ }^{\circ} \mathrm{C}$ at a $5{ }^{\circ} \mathrm{C} \mathrm{min}-1$ rate in a Setaram SDT 2960 thermobalance connected online with a Thermostar Balzers Instruments mass spectrometer (Cologne, Germany) ( $\mathrm{NH}_{3}$-TPD curves are provided in Figure S5). The Brönsted/Lewis (B/L) ratio of acidic sites was determined by FTIR spectrophotometry with adsorbed pyridine in a Thermo Nicolet 6700 unit. The main physico-chemical properties of the fresh catalysts are listed in Table 5. 
Table 5. Physico-chemical properties of the fresh CY and CZ catalysts.

\begin{tabular}{ccc}
\hline- & $\mathbf{C Y}$ & $\mathrm{CZ}$ \\
\hline $\mathrm{S}_{\mathrm{BET}}\left(\mathrm{m}^{2} \mathrm{~g}^{-1}\right)$ & 122 & 143 \\
$\mathrm{~V}_{\text {pore }}\left(\mathrm{cm}^{3} \mathrm{~g}^{-1}\right)$ & 0.35 & 0.24 \\
$\mathrm{~V}_{\text {micropore }}\left(\mathrm{cm}^{3} \mathrm{~g}^{-1}\right)$ & 0.04 & 0.02 \\
$\mathrm{~d}_{\mathrm{p}}(\AA)$ & 117.3 & 62.2 \\
Unit cell size $(\AA)$ & 24.30 & - \\
Total acidity $\left(\mu \mathrm{mol}_{\mathrm{NH} 3} \mathrm{~g}^{-1}\right)$ & 30 & 50 \\
Average acid strength $\left(\mathrm{kJ} \mathrm{mol}^{-1}\right)$ & 100 & 78 \\
B/L ratio $\left(\mathrm{mol} \mathrm{mol}^{-1}\right)$ & 0.75 & 0.22 \\
\hline
\end{tabular}

\subsection{Feedstock}

A blend of vacuum gasoil (VGO, $80 \mathrm{wt} . \%$ ) and a black poplar raw bio-oil (20 wt. $\%$ ) was used as feedstock. The VGO was supplied by Petronor S.A. (Somorrostro, S.A.). The raw bio-oil was obtained through fast pyrolysis of black poplar sawdust at $440-450{ }^{\circ} \mathrm{C}$, in a pilot plant from Ikerlan/IK-4 (Vitoria, Spain) provided with a conical spouted bed reactor (CSBR) [39]. The most relevant properties of the raw bio-oil and VGO are detailed in Table S1, Table S4, and Table S5 of the Supporting Material, respectively. The high amount of water in bio-oil (of $46.5 \mathrm{wt} . \%$ ) should be highlighted, since it is known to aid dispersion of heavy feed molecules in VGO conversion [40].

The elemental composition of the feeds (CHNS, oxygen was computed by difference) was measured by means of elemental analysis in a TruSpec CHM Macro and additional TruSpec S module by Leco (St. Joseph, MI, USA). The water content in the raw bio-oil was quantified through Karl Fischer titration in a Metrohm 830 KF Titrino plus. The chemical composition of the feeds was analyzed by GC-MS in a GC-MS QP2010 unit by Shimadzu (Kyoto, Japan). The simulated distillation data were obtained by gas chromatography analysis in a 6890 Series GC System by Agilent (Santa Clara, CA, USA) equipped with a flame ionization detector (FID) and using a Simdis D-2887 Fast/Ext. column.

\subsection{Catalytic Cracking Runs and Product Analysis}

The catalytic cracking runs of the VGO/bio-oil blend have been carried out in a CREC (Chemical Reactor Engineering Center) riser simulator (described in Scheme 1) designed to operate in a laboratory scale and in conditions that resemble those of an industrial FCC unit [40,41]. The experimental conditions were: temperature, $500-530-560{ }^{\circ} \mathrm{C}$; contact time, $6 \mathrm{~s}$; and catalyst/feed mass ratio (in a dry basis), $6 \mathrm{~g}_{\text {cat }} \mathrm{g}_{\text {bio-oil }}{ }^{-1}$. Blank runs in no-catalyst conditions using only a $\alpha-\mathrm{Al}_{2} \mathrm{O}_{3}+$ bentonite mixture were performed in order to confirm the inert nature of the matrix and binder used in the $\mathrm{CZ}$ catalyst preparation.

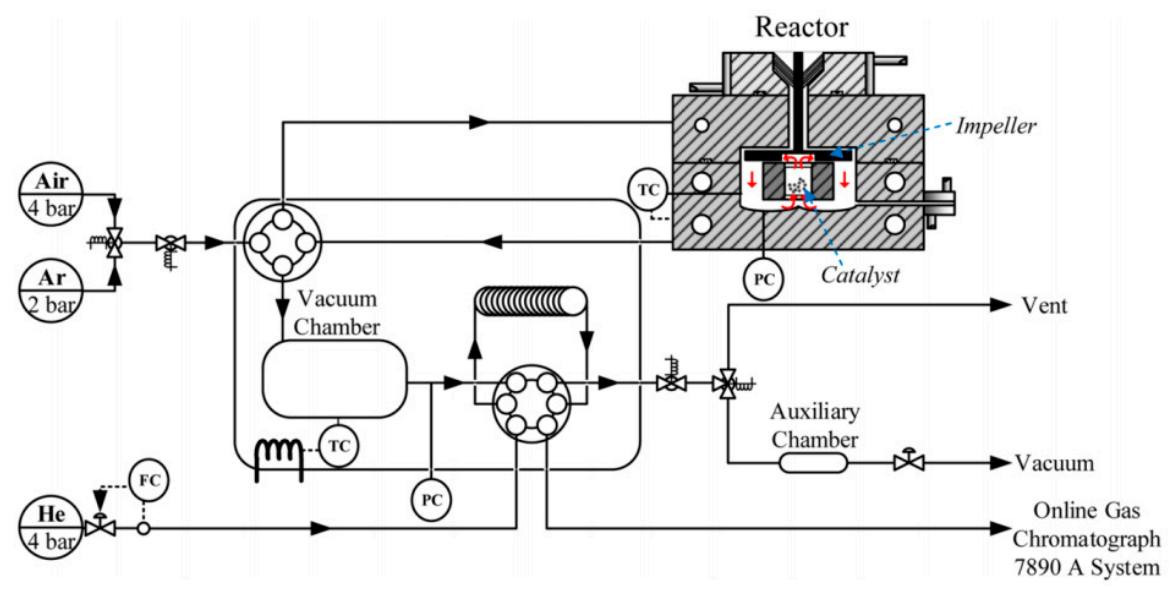

Scheme 1. Detailed schematization of the fluid catalytic cracking (FCC) unit riser simulator [21]. 
Once the reaction time was completed, the product stream was extracted from the reaction chamber through a rapidly triggered vacuum pump connected to an auxiliary chamber $\left(30 \mathrm{~cm}^{3}\right)$, and then analyzed online by means of gas chromatography (GC) in an Agilent Technologies 7890A chromatograph provided with flame ionization detector (FID). A gas sample was also collected from the chamber in order to quantify $\mathrm{CO}$ and $\mathrm{CO}_{2}$ in a Varian CP-4900 micro-chromatograph provided with two modules: (i) a molecular sieve (MS-5, $10 \mathrm{~m}$ ) where $\mathrm{H}_{2}, \mathrm{O}_{2} \mathrm{~N}_{2}, \mathrm{CH}_{4}$, and $\mathrm{CO}$ are separated and (ii) a Porapak PPQ $(10 \mathrm{~m})$, which separates $\mathrm{H}_{2} \mathrm{O}, \mathrm{CO}_{2}$, and light products (methane, ethylene, ethane, propylene, propane, acetaldehyde, butanes, butenes, and acrolein).

The main cracking products were classified in lumps, as follows: $\mathrm{CO}+\mathrm{CO}_{2}$, dry gases $\left(\mathrm{C}_{1}-\mathrm{C}_{2}\right)$, liquefied petroleum gases ( $\left.L P G, C_{3}-C_{4}\right)$, gasoline $\left(C_{5}-C_{12}\right)$, light cycle oil ( $\left.L C O, C_{13}-C_{20}\right)$, heavy cycle oil ( $\left.\mathrm{HCO}, \mathrm{C}_{21+}\right)$, and coke. The amount of coke was quantified from the mass loss after combustion of spent catalysts in a TGA-Q $5000 \mathrm{TA}$ Instruments thermobalance, from $300{ }^{\circ} \mathrm{C}$ up to $550{ }^{\circ} \mathrm{C}$ at a $3^{\circ} \mathrm{C} \min ^{-1}$ heating rate.

The yield of each product fraction $\left(Y_{i}\right)$ was defined by Equation (1):

$$
Y_{i}=\frac{m_{i}}{m_{\text {Bio-oil }}+m_{V G O}} 100
$$

where $Y_{i}$ is the yield of fraction $i(\mathrm{wt} . \%), \mathrm{m}_{\mathrm{i}}$ is the produced mass fraction of product $I$, and $\mathrm{m}_{\text {Bio-oil }}$ and $\mathrm{m}_{\mathrm{VGO}}$ correspond to the mass of bio-oil (in a wet basis) and VGO in the feed, respectively.

The conversion of carbonaceous compounds in the VGO/bio-oil blend was calculated as the yield sum of these compounds.

The conversion of oxygenates of bio-oil $\left(X_{\text {oxygenates }}\right)$ was calculated from Equation (2):

$$
X_{\text {oxygenates }}=\frac{\left(m_{\text {Oxyg }}\right)_{\text {feed }}-\left(m_{\text {Oxyg }}\right)_{\text {fuel }}}{\left(m_{\text {Oxyg }}\right)_{\text {feed }}} 100
$$

where $\left(m_{O x y y}\right)_{\text {feed }}$ is the mass content of oxygenates in the raw bio-oil feed (on a dry bio-oil basis) and $\left(m_{O x y g}\right)_{\text {fuel }}$ is the mass content of oxygenates in the remaining bio-oil in the product.

Different parameters have been determined for evaluating the quality of the produced liquid fuel [42]. The deoxygenation degree ( $D O D$, in wt.\%) was calculated from the oxygen mass content in the liquid fuel and the oxygenates in the feedstock, as:

$$
D O D=\left(1-\frac{\left(m_{O}\right)_{\text {fuel }}}{\left(m_{O}\right)_{\text {feed }}}\right) 100
$$

The liquid fuel yield $\left(Y_{\text {fuel }}\right)$, referred to the mass contents of oxygenates in bio-oil and hydrocarbons in $V G O$, was defined as:

$$
Y_{f u e l}=\frac{m_{f u e l}}{m_{\text {Oxyg }}+m_{V G O}} 100
$$

where $m_{f u e l}$ is the mass of liquid fuel products $\left(\mathrm{C}_{5}{ }^{+}\right.$hydrocarbons and oxygenates), and $m_{O x y g}$ and $m_{V G O}$ are the mass of oxygenates in bio-oil and $V G O$ in the feed, respectively.

On the other hand, the oxygen/carbon mass ratio $\left(O_{x} / C, \mathrm{gog}_{\mathrm{C}}{ }^{-1}\right)$ was determined from the oxygen mass content $\left(m_{O}\right)$, divided by the carbon mass content $\left(m_{C}\right)$ in the fuel product, as:

$$
\frac{O_{x}}{C}=\frac{\left(m_{O}\right)_{f u e l}}{\left(m_{C}\right)_{f u e l}}
$$




\section{Conclusions}

The application of a hybrid catalyst $(\mathrm{CH})$, consisting of an $80 \mathrm{wt} . \%$ of a commercial FCC catalyst and $20 \mathrm{wt} . \%$ of a HZSM-5-based catalyst leads to remarkable differences in conversion, product yields, and composition on the catalytic cracking of a VGO/bio-oil (80/20 wt.\%) blend in the $500-560{ }^{\circ} \mathrm{C}$ temperature range. The conversion of oxygenates in the blend increases approximately in the same extent that the conversion of the carbonaceous compounds decreases (ca. $3 \mathrm{wt} . \%$ ) using the $\mathrm{CH}$ catalyst. This behavior can be attributed to the activity of the HZSM-5 zeolite in the conversion of oxygenates to hydrocarbon and the diffusional limitations within its micropore structure for the bulkier fraction in VGO (namely, light cycle oil, LCO; and heavy cycle oil, HCO). As a consequence, more deoxygenated gasoline is obtained due to the selective cracking of bio-oil oxygenates that occurs when using the hybrid catalyst. In addition, the LPG yield is also increased, mainly ethylene and butenes, which originate from gasoline overcracking. Regarding gasoline composition, the lower activity of the HZSM-5 zeolite in bimolecular hydrogen transfer reactions reduces the formation of aromatics in this fraction, hence producing a more olefinic gasoline with the hybrid catalyst in contrast to the commercial FCC catalyst, which presents a higher proportion of Brönsted sites, which favor aromatics formation. Furthermore, the utilization of the hybrid catalyst can also aid in partially preventing catalyst deactivation due to the hindrance of the condensation reactions that give way to coke precursors by the addition of the HZSM- 5 zeolite. Consequently, the results obtained in this work processing real feedstock and resembling industrial FCC unit conditions evidence that adding a HZSM-5-based additive to the commercial FCC catalyst is a suitable strategy for facilitating the production of fuels from a VGO/bio-oil blend.

Supplementary Materials: The following are available online at http://www.mdpi.com/2073-4344/10/10/1157/s1, Table S1. Elemental composition, water content, and simulated distillation data of the raw black poplar bio-oil; Figure S1. Comparison of the evolution with conversion of the yields of a) dry gas, b) LPGs, and c) gasoline in the cracking of the VGO/bio-oil blend using the two different catalysts $\left(\mathrm{C} / \mathrm{O}, 6 \mathrm{~g}_{\text {cat }} \mathrm{g}_{\text {feed }}{ }^{-1} ; \mathrm{t}, 6 \mathrm{~s}\right)$; Figure $\mathrm{S} 2$. Effect of reaction temperature on the yields of the a) $C_{1}-C_{2}$, b) $\left.C_{3}, c\right)$, and d) $C_{4}$ gas phase compounds in the catalytic cracking of the VGO/bio-oil blend. (CY, dashed green-yellow trend; $\mathrm{CH}$, continuous blue trend); Table S2. Comparison of the effect of temperature on the olefinity and iso-olefinity of the $C_{5}-C_{6}$ families in the gasoline fraction produced in the cracking of the VGO/bio-oil blend using the $\mathrm{CY}$ and $\mathrm{CH}$ catalysts $\left(\mathrm{C} / \mathrm{O}, 6 \mathrm{~g}_{\text {cat }} \mathrm{g}_{\text {feed }}{ }^{-1} ; \mathrm{t}\right.$, $6 \mathrm{~s})$; Table S3. Comparison of the effect of temperature on the iso-parafinity of the $C_{5}-C_{6}$ families in the gasoline fraction produced in the cracking of the VGO/bio-oil blend using the $\mathrm{CY}$ and $\mathrm{CH}$ catalysts $\left(\mathrm{C} / \mathrm{O}, 6 \mathrm{~g}_{\text {cat }} \mathrm{g}_{\mathrm{feed}}{ }^{-1} ; \mathrm{t}, 6 \mathrm{~s}\right)$; Figure S3. $\mathrm{N}_{2}$ adsorption-desorption isotherms for the fresh commercial FCC (CY) and HZSM-5 (CZ) catalysts; Figure S4. Wide-angle XRD patterns for the fresh commercial FCC (CY) and HZSM-5 (CZ) catalysts; Figure S5. $\mathrm{NH}_{3}$-TPD curves for fresh commercial FCC (CY) and HZSM-5 (CZ) catalysts; Table S4. Chemical composition of the raw black poplar bio-oil; Table S5. Physico-chemical properties of the VGO.

Author Contributions: Conceptualization: Á.I., I.H., J.M.A. and J.B.; formal analysis, Á.I., I.H., J.M.A. and J.B.; investigation, methodology, and data curation, Á.I., I.H.; writing—original draft preparation, Á.I., I.H.; writing-review and editing, I.H., J.M.A., J.B.; supervision, project administration, and funding acquisition, J.M.A. and J.B. All authors have read and agreed to the published version of the manuscript.

Funding: This work has been conducted with the financial support from the Ministry of Economy and Competitiveness of the Spanish Government (MINECO) (Project RTI2018-096981-B-I00), co-funded with FEDER funds, the Basque Government (Project IT1218-19), and the European Commission (Horizon 2020-MSCA RISE-2018, Contract No. 823745). Idoia Hita is thankful for her postdoctoral grant awarded by the Department of Education, University and Research of the Basque Government (Grant No. POS_2015_1_0035). Álvaro Ibarra is grateful for his PhD grant from the University of the Basque Country (UPV/EHU). Authors would also like to acknowledge Ikerlan/IK-4 for providing the raw bio-oil, as well as Petronor S.A. for providing the VGO and the equilibrated FCC catalyst for this study.

Conflicts of Interest: Authors declare no conflict of interest. 


\section{References}

1. De Bhowmick, G.; Sarmah, A.K.; Sen, R. Lignocellulosic biorefinery as a model for sustainable development of biofuels and value added products. Bioresour. Technol. 2018, 247, 1144-1154. [CrossRef] [PubMed]

2. Wang, C.; Zhang, X.; Liu, Q.; Zhang, Q.; Chen, L.; Ma, L. A review of conversion of lignocellulose biomass to liquid transport fuels by integrated refining strategies. Fuel. Process. Technol. 2020, 208, 106485. [CrossRef]

3. Valle, B.; Remiro, A.; García-Gómez, N.; Gayubo, A.G.; Bilbao, J. Recent research progress on bio-oil conversion into bio-fuels and raw chemicals: A review. J. Chem. Technol. Biotechnol. 2018, 94, 670-689. [CrossRef]

4. Hansen, S.; Mirkouei, A.; Diaz, L.A. A comprehensive state-of-technology review for upgrading bio-oil to renewable or blended hydrocarbon fuels. Renew. Sustain. Energy Rev. 2020, 118, 109548. [CrossRef]

5. Dai, L.; Zhou, N.; Li, H.; Deng, W.; Cheng, Y.; Wang, Y.; Liu, Y.; Cobb, K.; Lei, H.; Chen, P.; et al. Recent advances in improving lignocellulosic biomass-based bio-oil production. J. Anal. Appl. Pyrolysis. 2020, 149, 104845. [CrossRef]

6. Lazzari, E.; Schena, T.; Marcelo, M.C.A.; Primaz, C.T.; Silva, A.N.; Ferrão, M.F.; Bjerk, T.R.; Caramão, E.B. Classification of biomass through their pyrolytic bio-oil composition using FTIR and PCA analysis. Ind. Crop. Prod. 2018, 111, 856-864. [CrossRef]

7. Hita, I.; Cordero-Lanzac, T.; García-Mateos, F.J.; Azkoiti, M.J.; Rodríguez-Mirasol, J.; Cordero, T.; Bilbao, J. Enhanced production of phenolics and aromatics from raw bio-oil using HZSM-5 zeolite additives for PtPd/C and NiW/C catalysts. Appl. Catal. B Environ. 2019, 259, 118112. [CrossRef]

8. Carpenter, D.; Westover, T.L.; Czernik, S.; Jablonski, W. Biomass Feedstocks for Renewable Fuel Production: A Review of the Impacts of Feedstock and Pretreatment on the Yield and Product Distribution of Fast Pyrolysis Bio-Oils and Vapors. Green Chem. 2014, 16, 384-406. [CrossRef]

9. Wang, C.; Ding, H.; Zhang, Y.; Zhu, X. Analysis of property variation and stability on the aging of bio-oil from fractional condensation. Renew. Energy 2020, 148, 720-728. [CrossRef]

10. Mei, Y.; Chai, M.; Shen, C.; Liu, B.; Liu, R. Effect of methanol addition on properties and aging reaction mechanism of bio-oil during storage. Fuel 2019, 244, 499-507. [CrossRef]

11. Meng, J.; Moore, A.; Tilotta, D.; Kelley, S.; Park, S. Toward Understanding of Bio-Oil Aging: Accelerated Aging of Bio-Oil Fractions. ACS Sustain. Chem. Eng. 2014, 2, 2011-2018. [CrossRef]

12. Hita, I.; Cordero-Lanzac, T.; Bonura, G.; Cannilla, C.; Arandes, J.M.; Frusteri, F.; Bilbao, J. Hydrodeoxygenation of raw bio-oil towards platform chemicals over FeMoP/zeolite catalysts. J. Ind. Eng. Chem. 2019, 80, 392-400. [CrossRef]

13. Hita, I.; Cordero-Lanzac, T.; Bonura, G.; Frusteri, F.; Bilbao, J.; Castaño, P. Dynamics of carbon formation during the catalytic hydrodeoxygenation of raw bio-oil. Sustain. Energy Fuels 2020. [CrossRef]

14. Stefanidis, S.D.; Kalogiannis, K.G.; Lappas, A. Co-processing bio-oil in the refinery for drop-in biofuels via fluid catalytic cracking. Wiley Interdiscip. Rev. Energy Environ. 2017, 7, e281. [CrossRef]

15. Hita, I.; Arabiourrutia, M.; Olazar, M.; Bilbao, J.; Arandes, J.M.; Castaño, P. Opportunities and barriers for producing high quality fuels from the pyrolysis of scrap tires. Renew. Sustain. Energy Rev. 2016, 56, 745-759. [CrossRef]

16. Wu, L.; Yang, Y.; Yan, T.; Wang, Y.; Zheng, L.; Qian, K.; Hong, F. Sustainable design and optimization of co-processing of bio-oil and vacuum gas oil in an existing refinery. Renew. Sustain. Energy Rev. 2020, 130, 109952. [CrossRef]

17. Fogassy, G.; Thegarid, N.; Toussaint, G.; Van Veen, A.C.; Schuurman, Y.; Mirodatos, C. Biomass derived feedstock co-processing with vacuum gas oil for second-generation fuel production in FCC units. Appl. Catal. B Environ. 2010, 96, 476-485. [CrossRef]

18. Bertero, M.; Sedran, U. Coprocessing of Bio-oil in Fluid Catalytic Cracking. In Recent Advances in Thermo-Chemical Conversion of Biomass; Elsevier BV: Amsterdam, The Netherlands, 2015; pp. 355-381.

19. Pinho, A.; De Almeida, M.B.; Mendes, F.L.; Ximenes, V.L.; Casavechia, L.C. Co-processing raw bio-oil and gasoil in an FCC Unit. Fuel Process. Technol. 2015, 131, 159-166. [CrossRef] 
20. Lindfors, C.; Paasikallio, V.; Kuoppala, E.; Reinikainen, M.; Oasmaa, A.; Solantausta, Y. Co-processing of Dry Bio-oil, Catalytic Pyrolysis Oil, and Hydrotreated Bio-oil in a Micro Activity Test Unit. Energy Fuels 2015, 29, 3707-3714. [CrossRef]

21. Ibarra, Á.; Rodríguez, E.; Sedran, U.; Arandes, J.M.; Bilbao, J. Synergy in the Cracking of a Blend of Bio-oil and Vacuum Gasoil under Fluid Catalytic Cracking Conditions. Ind. Eng. Chem. Res. 2016, 55, 1872-1880. [CrossRef]

22. Pinho, A.D.R.; De Almeida, M.B.; Mendes, F.L.; Casavechia, L.C.; Talmadge, M.S.; Kinchin, C.M.; Chum, H.L. Fast pyrolysis oil from pinewood chips co-processing with vacuum gas oil in an FCC unit for second generation fuel production. Fuel 2017, 188, 462-473. [CrossRef]

23. Wang, C.; Venderbosch, R.; Fang, Y. Co-processing of crude and hydrotreated pyrolysis liquids and VGO in a pilot scale FCC riser setup. Fuel Process. Technol. 2018, 181, 157-165. [CrossRef]

24. Ibarra, Á.; Hita, I.; Azkoiti, M.J.; Arandes, J.M.; Bilbao, J. Catalytic cracking of raw bio-oil under FCC unit conditions over different zeolite-based catalysts. J. Ind. Eng. Chem. 2019, 78, 372-382. [CrossRef]

25. Wu, L.; Wang, Y.; Zheng, L.; Wang, P.; Han, X. Techno-economic analysis of bio-oil co-processing with vacuum gas oil to transportation fuels in an existing fluid catalytic cracker. Energy Convers. Manag. 2019, 197, 111901. [CrossRef]

26. Bhatt, A.; Zhang, Y.; Heath, G. Bio-oil co-processing can substantially contribute to renewable fuel production potential and meet air quality standards. Appl. Energy 2020, 268, 114937. [CrossRef]

27. Ibarra, Á.; Hita, I.; Arandes, J.M.; Bilbao, J. Influence of the Composition of Raw Bio-Oils on Their Valorization in Fluid Catalytic Cracking Conditions. Energy Fuels 2019, 33, 7458-7465. [CrossRef]

28. Corma, A.; Martínez, C.; Sauvanaud, L. New materials as FCC active matrix components for maximizing diesel (light cycle oil, LCO) and minimizing its aromatic content. Catal. Today 2007, 127, 3-16. [CrossRef]

29. Awayssa, O.; Al-Yassir, N.; Aitani, A.M.; Al-Khattaf, S. Modified HZSM-5 as FCC additive for enhancing light olefins yield from catalytic cracking of VGO. Appl. Catal. A Gen. 2014, 477, 172-183. [CrossRef]

30. Degnan, T.; Chitnis, G.; Schipper, P. History of ZSM-5 fluid catalytic cracking additive development at Mobil. Microporous Mesoporous Mater. 2000, 35, 245-252. [CrossRef]

31. Nishu; Liu, R.; Rahman, M.; Sarker, M.; Chai, M.; Li, C.; Cai, J. A review on the catalytic pyrolysis of biomass for the bio-oil production with ZSM-5: Focus on structure. Fuel Process. Technol. 2020, 199, 106301. [CrossRef]

32. Gayubo, A.G.; Valle, B.; Aguayo, A.; Olazar, M.; Bilbao, J. Olefin Production by Catalytic Transformation of Crude Bio-Oil in a Two-Step Process. Ind. Eng. Chem. Res. 2010, 49, 123-131. [CrossRef]

33. Ibarra, Á.; Veloso, A.; Bilbao, J.; Arandes, J.M.; Castaño, P. Dual coke deactivation pathways during the catalytic cracking of raw bio-oil and vacuum gasoil in FCC conditions. Appl. Catal. B Environ. 2016, 182, 336-346. [CrossRef]

34. Valle, B.; Gayubo, A.G.; Alonso-Vicario, A.; Aguayo, A.; Bilbao, J. Hydrothermally stable HZSM-5 zeolite catalysts for the transformation of crude bio-oil into hydrocarbons. Appl. Catal. B Environ. 2010, 100, 318-327. [CrossRef]

35. Ibáñez, M.; Valle, B.; Bilbao, J.; Gayubo, A.G.; Castaño, P. Effect of operating conditions on the coke nature and HZSM-5 catalysts deactivation in the transformation of crude bio-oil into hydrocarbons. Catal. Today 2012, 195, 106-113. [CrossRef]

36. Valle, B.; Castaño, P.; Olazar, M.; Bilbao, J.; Gayubo, A.G. Deactivating species in the transformation of crude bio-oil with methanol into hydrocarbons on a HZSM-5 catalyst. J. Catal. 2012, 285, 304-314. [CrossRef]

37. Arandes, J.M.; Abajo, I.; Fernández, I.; Azkoiti, M.J.; Bilbao, J. Effect of HZSM-5 Zeolite Addition to a Fluid Catalytic Cracking Catalyst. Study in a Laboratory Reactor Operating under Industrial Conditions. Ind. Eng. Chem. Res. 2000, 39, 1917-1924. [CrossRef]

38. Epelde, E.; Aguayo, A.; Olazar, M.; Bilbao, J.; Gayubo, A.G. Modifications in the HZSM-5 zeolite for the selective transformation of ethylene into propylene. Appl. Catal. A Gen. 2014, 479, 17-25. [CrossRef]

39. Makibar, J.; Fernández-Akarregui, A.R.; Amutio, M.; Lopez, G.; Olazar, M. Performance of a conical spouted bed pilot plant for bio-oil production by poplar flash pyrolysis. Fuel Process. Technol. 2015, 137, 283-289. [CrossRef]

40. de Lasa, H. Novel Riser Reactor Simulator. U.S. Patent No. 5,102,628, 1992. accessed in August 2020. 
41. Passamonti, F.; De La Puente, G.; Sedran, U. Comparison between MAT Flow Fixed Bed and Batch Fluidized Bed Reactors in the Evaluation of FCC Catalysts. 2. Naphtha Composition. Energy Fuels 2009, 23, 3510-3516. [CrossRef]

42. Mortensen, P.M.; Grunwaldt, J.-D.; Jensen, P.A.; Knudsen, K.; Jensen, A.D. A review of catalytic upgrading of bio-oil to engine fuels. Appl. Catal. A Gen. 2011, 407, 1-19. [CrossRef] 